\title{
But You Promised: Children’s Judgments of Broken Promises
}

\author{
Karen Hussar, Jared Horvath \\ Fisher College, Boston, USA \\ Email: khussar@fisher.edu, jch155@mail.harvard.edu
}

Received May $1^{\text {st }}$, 2013; revised June $3^{\text {rd }}, 2013$; accepted July $2^{\text {nd }}, 2013$

\begin{abstract}
Copyright (c) 2013 Karen Hussar, Jared Horvath. This is an open access article distributed under the Creative Commons Attribution License, which permits unrestricted use, distribution, and reproduction in any medium, provided the original work is properly cited. In accordance of the Creative Commons Attribution License all Copyrights (C) 2013 are reserved for SCIRP and the owner of the intellectual property Karen Hussar, Jared Horvath. All Copyright $(2013$ are guarded by law and by SCIRP as a guardian.
\end{abstract}

\begin{abstract}
Current conceptions regarding children's understanding of promises (and promise breaking) rely upon absolute distinction: namely, a promise versus a non-promise. The current study expands the understanding of children's judgments of broken promises to include more nuanced, refined descriptions. Utilizing a four-point rating scale-ranging from "OK" to "very bad"—-forty children aged 6 to 10 judged story cards depicting characters breaking commitments not to engage in specific behaviors across three different domains (moral, social-conventional, and personal). Analyses indicated that children judge broken promises in the moral domain more severely than those in the social-conventional domain and broken promises in the social-conventional domain more severely than those in the personal domain. Therefore, children appear to judge broken commitments on a sliding scale in much the same way they judge actions from the moral, social-conventional and personal domains. Results from the current study also suggest an inverse pattern of judgment with regards to broken commitments. Specifically, it appears that the more severely an initial action is judged, the less severely its concurrent commitment condition is judged; and vice versa. These findings help refine our understanding of childhood interpretations of broken promises and engender several unique ideas for future research in this field.
\end{abstract}

Keywords: Commitment; Promises; Morality; Social Domain Theory

\section{Introduction}

A hallmark of childhood psychological research is the progression from diametric classification to a more detailed spectrum of designation. For instance, Piaget and Kohlberg, pioneers in the field of moral development, focused on a near absolute emergent moral distinction between right and wrong. Subsequent social domain theorists expanded this perception and developed a more nuanced prescriptivity scale that allowed children to judge various actions according to a spectrum, typically ranging between "OK" and "very bad". The introduction of this refined rating system advanced research in the field of moral development by revealing the ability of young children to reliably distinguish between moral transgressions, social-conventional transgressions, and personal choices (Nucci \& Turiel, 1978; Smetana, 1981; Smetana \& Braeges, 1990).

Similarly, early research examining lying among young children focused on the ability of these children to distinguish between lies and truth. Only when these initial boundaries were delineated were researchers able to examine children's refined distinctions between different types of lying. Presently, there is strong evidence to support the idea that children as young as 7 can readily distinguish between antisocial lies (lies intended to conceal or mislead- “It was like that when I got here.”), prosocial lies (lies intended to be polite- “I love your new haircut.”), and trick lies (lies intended to elicit joy or laughter- "Got your nose!”). By age 9, children often judge "antisocial” lies more severely than "prosocial lies" and "prosocial lies" more se- verely than "trick lies” (Bussey, 1999; Fu, Xu, Cameron, Heyman, \& Lee, 2007; Lee, Xu, Fu, Cameron, \& Chen, 2001; Xu, Boa, Fu, Talwar, \& Lee, 2010).

The present study continues this progression from dichotomous classification to nuanced designation with regards to children's understandings of promises. Through the use of a sliding rating scale-similar to one employed by social domain theorists - we expand the current understanding of children's judgments of broken promises.

\section{Promises and Children}

Philosopher John Searle (1969) outlined a series of conditions that must be met in order for a successful "promise" to be made. These conditions include obligation (a "promiser" makes a commitment to undertake a certain action), controllability (a promise must be physically and/or mentally possible to perform), and advantage (a promise must prove advantageous or beneficial to the "promisee"-promise to harm is no longer a promise; it is a threat). Perhaps the most important aspect of Searle's description of promising is the nugatory nature of outcome. Whether fulfilled or not, the very act of saying "I promise” engenders an expectation in the listener. Accordingly, the "promiser" is held accountable and the promise remains valid regardless of the outcome. For example, a mother's failure to appear at a class play she promised to attend does not negate the previously made promise. The claim that individuals view a promise as valid irrespective of outcome has been confirmed in 
several studies using adult subjects (Astington, 1988, 1990; Gibbs \& Delaney, 1987).

Searle's notion of an explicit obligation points to an important distinction between lying and promise breaking. Lying is an act of verbal and/or emotional deception meant to engender a false belief. Conversely, a broken promise reneges on a prior commitment. Whether or not a promise is kept, the initial intention to perform the promised act (obligation) is inherently different from the initial intent to deceive by lying. We highlight this point because, although there is a long tradition of research exploring children's understanding of lying, research exploring children's understanding of promises and their ensuing commitments did not emerge until quite recently-and, even today, the literature is quite sparse and diametric.

In one of the first looks at promissory understanding, Astington (1988), through the use of utterances embedded in oral narratives, determined that children between the ages of $5-7$ were unable to grasp the concept of obligation. As a result, the children classified a statement as a promise only if the promised event occurred. More specifically, participants in this study considered the statement, "I will take you [to the store], I promise," as a valid promise only if the characters went to the store. Astington concluded that the ability to recognize that a promise remains valid regardless of outcome does not begin to emerge until age seven.

While ultimately confirming Astington's findings, several researchers have demonstrated that the distinction between promise and outcome is somewhat tenuous even beyond the age of 7. For instance, using stories that featured characters making and breaking promises to one another, Maas and Abbeduto (2001) found that 9-year-olds, although able to assign responsibility to the "promiser" for the outcome, often acknowledged obligation only if a clear and involuntary obstacle impeded the said "promiser" from fulfilling the promise. For example, when Nevin did not show up to play on the swings with Corrinda after he had promised he would do so, many 9-year-old participants saw this as a broken promise even when it was explained Nevin failed to show up due to illness. However, when Nevin simply went home to play alone, these same participants did not view this act as a broken promise. Similarly, Mant and Perner (1988), using oral narratives featuring characters breaking promises for various reasons (both intentionally and unintentionally in much the same manner as the Nevin character described above), concluded that the ability to consistently and accurately assign obligation to the "promiser" does not emerge until the age of 9 or 10 .

In order to further define the boundaries of young children's understanding of promises, Maas (2008) used videotaped stories employing thought bubbles to reveal the inner-thoughts of characters. Utilizing this methodology, Maas examined the impact of "promiser" sincerity and intention on 4- to 6-yearolds' ability to correctly identify promises. As an example, after promising to help rake leaves, a "sincere" character's thought bubble might say, "I DO want to help-I ALWAYS like to help," while an insincere character's thought bubble might say, "I DO NOT want to help-I will NEVER want to help." Mass determined that although children as young as 4 can-and do-successfully identify promises made with sincere intentions, the ability to identify promises regardless of intention begins to emerge by age 6 . In her conclusion, Maas argued that childhood understanding of promises progresses from a focus on outcome to a focus on the belief promises create in the lis- tener.

When combined with Maas's earlier work, it appears promissory comprehension evolves from responsibility to obligation and ends with expectation. Unfortunately, as noted above, due to the dearth of research examining this topic, such syntheses can only be hypothesized. In addition, it is important to note that each of the aforementioned studies utilized a diametric scale rather than a more nuanced "sliding" scale. More specifically, participants were asked to categorize each scenario as a broken promise or not.

\section{Synthesizing Moral Development and Understanding of Promises}

Piaget and Kohlberg's foundational research in the field of moral reasoning focused on stage-like moral development; however, succeeding developmental psychologists-namely Turiel, Nucci and Smetana-investigated the reasoning behind children's moralistic categorization of specific actions. Based on a series of studies (Nucci \& Turiel, 1978; Nucci, 1981; Nucci, Turiel, \& Encarnacion-Gawrych, 1983; Smetana, 1981; Smetana, 1985; Turiel, 1983; Turiel, 2002), these domain theorists concluded that children as young as three years old can readily differentiate between moral transgressions (actions that cause physical or psychological harm to others, such as hitting or teasing), social-conventional transgressions (actions that violate the social order, such as not sitting in an assigned seat or cutting in line), and personal choices (actions that reflect personal preference, such as wearing a certain brand of clothing or participating in a particular sport).

Hussar and Harris (2009) utilized this non-diametric moral domain-theory framework to examine children's understanding of personal "promiser" commitment. More specifically, this research examined whether children viewed a failed promise made to one's self (in this case, "I will not eat meat.") as a binding commitment. Using story cards in which characters made and broke promises not to eat meat for moral reasons (e.g., "Animals are my friends and I don't want to hurt them.”) and personal reasons (e.g., "I just don’t like the taste.”), they found that both vegetarian and non-vegetarian participants did indeed judge failure to adhere to a commitment to vegetarianism as wrong. However, participants judged the breaking of a commitment more severely if it was made for moral as opposed to personal reasons. Thus children varied in their judgments of this broken commitment depending on whether the person's initial motive for making it fell into the moral domain or the personal domain.

\section{The Current Study}

The current study aimed to expand Hussar and Harris's research (2009). Participants in the current study were asked to judge individuals who broke commitments across various domains. Specifically, participants were asked to judge individuals who broke personal commitments (e.g., a commitment to be physically active), social-conventional commitments (e.g., a commitment to be tidy) and moral commitments (e.g., a commitment to stop bullying classmates) using a scale comparable to the one utilized by social domain theorists. The authors hypothesized that children would judge broken commitments in the same manner they judge actions from the moral, socialconventional and personal domains. Specifically, participants would judge broken commitments from the moral domain more 
severely than broken commitments from the social-conventional domain and broken commitments from the social-conventional domain more severely than broken commitments from the personal domain. By establishing children's judgments toward various broken commitments, we hope to determine if children judge the breaking of a commitment in terms of the initial grounds for making it.

\section{Method}

\section{Participants}

Participants were 40 middle-class children ranging from 6 to 10 years of age $(M=7$ years 7 months, $S D=1.37)$. There were an equal number of boy and girl participants; all were Caucasian. Participants were recruited in suburban neighborhoods surrounding two major northeast metropolitan areas in the United States.

\section{Design and Procedure}

The first author conducted all interviews individually with each participant during a single visit to either the participant's home or school. Before the interview began, participants were told that the researcher was "talking with kids like you to find out what things different children think are OK to do and what things children think are bad to do.” Each interview lasted between 30 - 45 minutes and was audio-taped and subsequently transcribed.

To provide an initial assessment of children's evaluation of actions falling into the moral, social-conventional, and personal domains, children were presented in a random order with twelve story cards depicting four moral transgressions (stealing a quarter from a classmate; pushing a classmate out of the way so as to be first in line; grabbing a toy from a classmate; hitting a classmate); four social-conventional transgressions (eating salad with fingers; not pushing in a chair upon dismissal from class; leaving a dirty wrapper on the table after a snack; not sitting in an assigned seat in class); and four personal choices (reading during recess; coloring a drawing with a purple crayon; eating junk food; sleeping in on a Saturday morning). The gender of the story card character matched the gender of the participant (Susan for girls, Sam for boys). Children were asked to judge each depicted action as "OK”, "a little bad”, "bad”, or "very bad". Initially, the interviewer did not provide any background information about the story character. Thus, children were left to make their own assumptions about the individual.

After this initial exercise, children were asked to judge the twelve events again; however, this time the interviewer told participants that the story character had made a commitment not to engage in the action in question before performing it (e.g., Sam promised not to take things that did not belong to him, but stole a quarter from his classmate's desk; Susan promised to be more active, but decided to read a book during recess). Once children learned about each prior commitment, they then judged each depicted action as "OK”, “a little bad”, "bad”, or "very bad".

\section{Results}

Figure 1(a) reveals that participants judged moral transgressions more severely than social-conventional transgressions and rarely condemned personal choices. To analyze these results, a repeated measures ANCOVA of Domain (moral, social- conventional, personal) $X$ Age $(6,7,8,9,10)$ was conducted with the participants' gender included as a covariate. This analysis produced a significant main effect of Domain, $F(1,34)=$ 229.69, $p<0.001$, but no main effect of Age, $F(4,34)=1.25, p$ $=0.31$. The covariate, Gender, was not a statistically significant predictor of the outcome $(p=0.14)$.

Figure 1(b) indicates that when participants were told that the story character made a commitment (promise) not to engage in the action in question, they typically judged moral transgressions more severely than social-conventional transgressions and social-conventional transgressions more severely than personal choices. To analyze these results, a repeated measures ANCOVA of Domain (moral, social-conventional, personal) $\mathrm{X}$ Age $(6,7,8,9,10)$ was conducted with the participants' gender included as a covariate. This analysis produced a significant main effect of Domain, $F(1,34)=288.19, p<0.001$, but no main effect of Age, $F(4,34)=0.93, p=0.46$. The covariate, Gender, was not a statistically significant predictor of the outcome $(p=0.25)$.

Figure 1(c) demonstrates that within each of the three domains, participants' judgments were more severe if they were told that the story character initially made a promise not to engage in the action in question. Contrast analyses confirm that participants judged identical moral transgressions more severely when it was made explicit that the character had promised not to transgress prior to acting, $F(1,34)=12.49, p<0.01$, identical social-conventional transgressions more severely when it was made explicit that the character had promised not to transgress prior to acting, $F(1,34)=16.01, p<0.001$, and identical personal choices more severely when it was made explicit that the character promised not to transgress prior to acting, $F(1,34)=43.51, p<0.001$.

In summary, participants were sensitive to the domain under consideration, both when they were given no background information on the story character's intentions and when they were told that the story character made a promise not to engage in the action in question. Nevertheless, within each of the three domains, participants consistently judged the story character more severely for his/her actions when the story character initially made a commitment not to engage in the action in question.

\section{Discussion}

The goal of this study was to determine if children consider the breaking of commitments (promises) to vary in degree of wrongness. Specifically, we asked whether children would judge any form of failed commitment similarly or whether they would differentially judge broken commitments according to the initial basis for the commitment. We began our analyses by confirming that our participants judged events within the moral, social-conventional and personal domains in a pattern identical to what domain theorists have established (e.g., Smetana, 2006; Turiel, 2006). On average, participants judged moral transgressions more severely than social-conventional transgressions and judged social-transgressions more severely than personal choices. In fact, participants were reluctant to pass judgment on personal choices in general (see Figure 1(a)).

With respect to commitments broken within each of these three domains, our results indicate that children judged broken promises in the moral domain more severely than those in the 


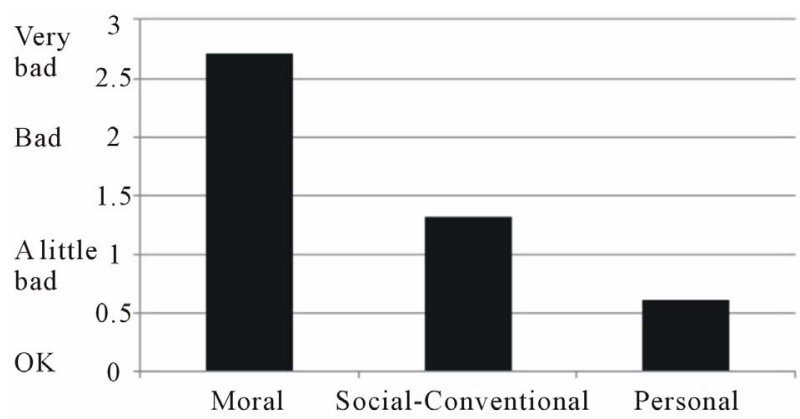

(a)

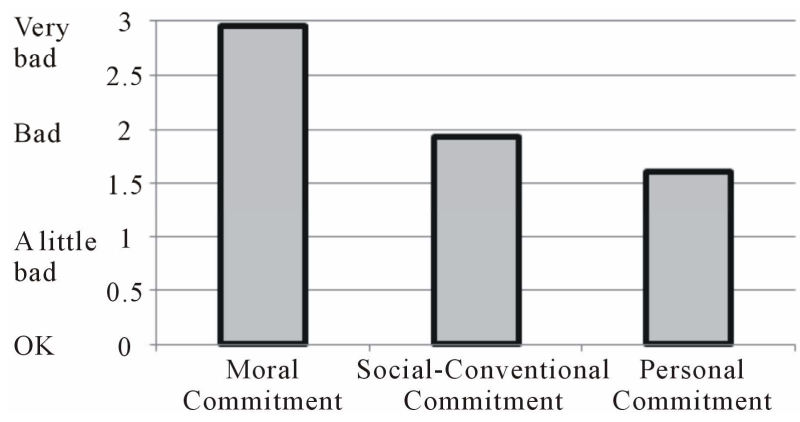

(b)

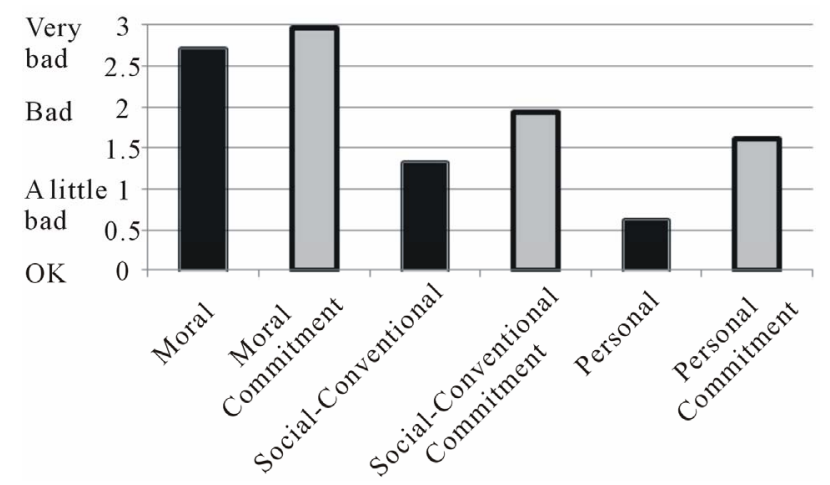

(c)

Figure 1.

(a) Participants' average judgments of three domains (moral, socialconventional, and personal) $(\mathrm{N}=40)$. Responses reflect a four-point scale where 0 = OK, 1 = a little bad, 2 = bad, 3 = very bad. (b) Participants' average judgments of three domains (moral, social-conventional, and personal) after learning that the story character promised not to transgress prior to acting $(\mathrm{N}=40)$. Responses reflect a four-point scale where 0 = OK, 1 = a little bad, 2 = bad, 3 = very bad. (c) Participants' average judgments of three domains (moral, social-conventional, and personal) across two conditions (no background information on story character and committed story character) $(\mathrm{N}=40)$. Responses reflect a four-point scale where $0=\mathrm{OK}, 1=$ a little bad, 2 = bad, $3=$ very bad.

social-conventional domain and broken promises in the social-conventional domain more severely than those in the personal domain (see Figure 1(b)). Therefore, it appears that children judge broken commitments on a sliding scale in much the same way they judge actions from the three specified domains. Below, we consider two plausible explanations as to why children do not judge broken commitments in a uniform manner.

A comparison of the promise/non-promise scenarios reveals that across all three domains, participants' judgments were more severe when the story card character initially made a promise not to engage in the action in question (see Figure 1(c)). On average, judgments shift by approximately one rating on the ordinal scale: from "OK" to "a little bad" within the personal domain; from "a little bad" to "bad" within the socialconventional domain; and from "bad" to "very bad" within the moral domain. Under this interpretation, participants judge the breaking of all promises similarly. What differs is the initial judgment of the actions in question (as evidenced in Figure 1(a)). This explanation is reinforced by several participants' unprompted comments. For instance, in reference to the scenario where Susan breaks her promise to be more active at recess, one child replied, "It wouldn't have been so bad...but she breaks a promise so it goes down one [italics added].” Another participant expressed a similar viewpoint: "I guess all the ones where [Susan] promises might be one worse...because she made a promise and broke it [italics added].” These references to intensifying a judgment by "one” suggest a consistent judgment assigned to the act of breaking a promise, regardless of the associated behavior.

Although this interpretation is compelling, a closer examination of the data casts doubt on this theory. If this explanation were correct, we would have expected to see a near identical judgment differential (“one”) between the non- and brokenpromise scenarios across each domain. However, when numerically calculated (as opposed to simply assigning an ordinal rank), this difference appears to shift between scenariosreaching, on average, 1 point in the personal domain, 0.50 points in the social-conventional domain, and 0.25 points in the moral domain. Accordingly, despite the homogenous ranking method alluded to by several participants, it appears that, on average, our participants differentially judged commitment conditions according to each unique circumstance.

These numerical calculations suggest an alternative explanation for our results, one we believe corresponds with the pattern of results initially established by domain theorists. As previously noted, our participants were reluctant to assign any judgment to the personal choices made by the story card characters. However, once the character made and broke a promise not to engage in the described personal action, participants negatively judged their behavior ("a little bad", on average). Accordingly, these negative judgments can be understood to exclusively reflect the act of breaking the promise. Conversely, our participants, on average, initially judged moral transgressions as "very bad". However, when a promise condition was introduced and broken within the moral domain, this judgment shifted only slightly ( 0.25 points). This small shift in judgment suggests that our participants viewed the breaking of a promise not to engage in a moral transgression as almost inconsequential, particularly as it compares to the moral transgression itself. In other words, it appears that the more severely an initial action is judged, the less severely its concurrent commitment will be judged. Accordingly, the less severely an initial action is judged, the more severely its concurrent commitment condition will be judged.

Although certainly suggested by our data, we believe this "inverse commitment" theory could be better tested with a more sensitive sliding scale upon which participants judge non-promise/promise scenarios. Whereas our scale may have led to a ceiling effect within the moral domain, a five-point scale ranging from "OK" to "very, very bad" would allow researchers to better determine judgments toward broken moral commitments and perhaps confirm this relationship between original action and related commitment. Regardless, the data 
collected in the current study supports this hypothesis.

In addition, it is important to note that the age range of our participants (6 - 10 years old) may have influenced participants' judgments of the actions in question. As demonstrated by earlier researchers (i.e., Maas \& Abbedutio, 2001; Mant \& Perner, 1988), mature comprehension of made-, kept- and brokenpromises emerges around age 7 but remains somewhat fragile until later adolescence. Perhaps the vacillation in our procedures between traditional moral-domain judgments and broken commitment judgments is a symptom of this maturation. Future research could also determine if the aforementioned results are replicated with older children (i.e., 11 - 12 years old) or if varied judgments towards broken commitments stabilizes with age.

In the end, this study has generated some unique and interesting results. It initially appeared that young children were differentially rating commitment scenarios (e.g., judging those broken commitments that result in physical or psychological harm towards others more severely than those broken commitments that result in a disruption to the social order). However, when the promise scenario is decoupled from its related event, the opposite may actually be true: young children judge broken commitments to moral transgressions less severely than broken commitments to personal choices. The message presented seems to be one of caliber: when one breaks a promise not to engage in a moral transgression, the broken promise is superseded by the moral transgression itself and, accordingly, is not judged harshly (e.g., "S/he should have known better.”). Conversely, when one breaks a promise not to engage in a personal choice, the broken promise is the only true transgression and, accordingly, is judged somewhat severely (e.g., "Why did s/he say it if s/he didn't mean it?”). This concept implies children are sensitive to personal commitments, particularly broken personal commitments. As such, our findings suggest that educators and other professionals working with young children may need to mitigate the judgments children are likely to bestow on others when personal commitments are broken (e.g., dropping out of a school club; quitting a sports team; canceling a scheduled social activity).

Therefore, with regards to our research question, children do consider the initial basis for which a commitment was made in determining the severity of their judgment of the broken commitment in question. However, their judgments appear to be more sophisticated that initially theorized. The more severely an initial action is judged, the less severely its concurrent commitment will be judged. Accordingly, the less severely an initial action is judged, the more severely its concurrent commitment condition will be judged. Although certainly suggested by our data, we believe this "inverse commitment" theory should be confirmed through future research that includes a more sensitive judgment scale as well as a wider age range of participants.

\section{REFERENCES}

Astington, J. W. (1988). Children's understanding of the speech act of promising. Journal of Child Language, 15, 157-173. http://dx.doi.org/10.1017/S0305000900012101

Astington, J. W. (1990). Metapragmatics: Children's conception of promising. In G. Conti-Ramsden, \& C. Snow (Eds.), Children's language: Vol. 7 (pp. 223-244). Hillsdale, NJ: Erlbaum.

Bussey, K. (1999). Children's categorization and evaluation of different types of lies and truths. Child Development, 70, 1338-1347. http://dx.doi.org/10.1111/1467-8624.00098

Fu, G., Xu, F., Cameron, C. A., Heyman, G., \& Lee, K. (2007). Crosscultural differences in children's choices, categorizations, and evaluations of truths and lies. Developmental Psychology, 43, 278-293. http://dx.doi.org/10.1037/0012-1649.43.2.278

Gibbs, R. W., \& Delaney, S. M. (1987). Pragmatic factors in making and understanding promises. Discourse Processes, 10, 107-126. http://dx.doi.org/10.1080/01638538709544662

Hussar, K. M., \& Harris, P. L. (2009). Children who choose not to eat meat: A study of early moral decision-making. Social Development, 19, 627-641. http://dx.doi.org/10.1111/j.1467-9507.2009.00547.x

Lee, K., Xu, F., Fu, G., Cameron, C. A., \& Chen, S. (2001). Taiwan and Mainland Chinese and Canadian children's categorization and evaluation of lie- and truth-telling: A modesty effect. British Journal of Developmental Psychology, 19, 525-542. http://dx.doi.org/10.1348/026151001166236

Maas, F. K., \& Abbeduto, L. (2001). Children's judgments about intentionally and unintentionally broken promises. Journal of Child Language, 28, 517-529. http://dx.doi.org/10.1017/S0305000901004743

Maas, F. K. (2008). Children's understanding of promising, lying, and false belief. The Journal of General Psychology, 135, 301-321. http://dx.doi.org/10.3200/GENP.135.3.301-322

Mant, C. M., \& Perner, J. (1988). The child's understanding of commitment. Developmental Psychology, 24, 343-351. http://dx.doi.org/10.1037/0012-1649.24.3.343

Nucci, L. P., \& Turiel, E. (1978). Social interactions and the development of social concepts in pre-school children. Child Development, 49, 400-407. http://dx.doi.org/10.2307/1128704

Nucci, L. (1981). Conceptions of personal issues: A domain distinct from moral or societal concepts. Child Development, 52, 114-121. http://dx.doi.org/10.2307/1129220

Nucci, L., Turiel, E., \& Encarnacion-Gawrych, G. (1983). Children's social interactions and social concepts: Analyses of morality and convention in the Virgin Islands. Journal of Cross-Cultural Psychology, 14, 469-487. http://dx.doi.org/10.1177/0022002183014004006

Searle, J. (1969). Speech acts: An essay in the philosophy of language. New York: Cambridge University Press. http://dx.doi.org/10.1017/CBO9781139173438

Smetana, J. (1981). Preschool children's conceptions of moral and social rules. Child Development, 52, 1333-1336. http://dx.doi.org/10.2307/1129527

Smetana, J. (1985). Preschool children's conceptions of transgressions: The effects of varying moral and conventional domain-related attributes. Developmental Psychology, 21, 18-29. http://dx.doi.org/10.1037/0012-1649.21.1.18

Smetana, J., \& Braeges, J. L. (1990). The development of toddlers' moral and conventional judgments. Merrill-Palmer Quarterly, 36, 329-346.

Smetana, J. (2006). Social domain theory: Consistencies and variations in children's moral and social judgments. In M. Killen, \& J. Smetana (Eds.), Handbook of moral development (pp. 119-154). Hillsdale, NJ: Erlbaum.

Turiel, E. (1983). The development of social knowledge. Cambridge: Cambridge University Press.

Turiel, E. (2002). The culture of morality: Social development, context, and conflict. Cambridge: Cambridge University Press. http://dx.doi.org/10.1017/CBO9780511613500

Turiel, E. (2006). The development of morality. In N. Eisenberg, W. Damon, \& R. M. Lerner (Eds.), Handbook of child psychology: Social, emotional, and personality development (pp. 789-857). Hoboken, NJ: Wiley.

Xu, F., Bao, X., Fu, G., Talwar, V., \& Lee, K. (2010). Lying and truth-telling in children: From concept to action. Child Development, 81, 581-596. http://dx.doi.org/10.1111/j.1467-8624.2009.01417.x 